\title{
HAEMATOLOGICAL DISORDERS DIAGNOSED IN ONE HUNDRED AND ONE SUCCESSIVE BONE MARROW EXAMINATION AT A TERTIARY CARE CENTRE IN QUETTA, BALOCHISTAN
}

\author{
Sunila Tashfeen, Naveed Asif, Shafia Nasir, Muhammad Azam, Zareen Irshad* \\ Combined Military Hospital Quetta/National University of Medical Sciences (NUMS) Pakistan, *Jinnah Sindh Medical University, Karachi Pakistan
}

\begin{abstract}
Objective: To determine the frequency of haematological disorders diagnosed by bone marrow examination at a tertiary care centre in Quetta, Balochistan.

Study Design: Prospective observational study.

Place and Duration of Study: Department of Pathology, Combined Military Hospital Quetta, from Jan 2018 to May 2019.

Methodology: A total of 101 one patients, who underwent bone marrow examination, were included in the study. Brief history, clinical examination and indication of procedure were also endorsed in a questionnaire designed for the study.

Results: Bone marrow of one hundred and one patients, included in the study, were evaluated. Mean age of the patients was $32.3 \pm 18.4$ years. There were 68 males $(67 \%)$, while 33 were females (33\%) with 2:1 male to female ratio. Pyrexia of unknown origin (PUO) was the most common indication for bone marrow examination with frequency of $20.7 \%$. Nutritional anaemia was the most prevalent benign disorder (17\%), whereas Acute Lymphoblastic leukaemia (ALL) accounted about $6.8 \%$ which is highest in malignant disorders.

Conclusion: This study has concluded that bone marrow examination is a useful technique and findings of bone marrow can modify the treatment. Thus procedure has a great diagnostic value. Both bone marrow aspiration (BMA) and bone marrow biopsy (BMB) are the complimentary techniques and supremacy of one method on other depends on the disorder.
\end{abstract}

Keywords: Aspiration, Bone marrow, Trephine biopsy.

This is an Open Access article distributed under the terms of the Creative Commons Attribution License (http://creativecommons.org/licenses/by/4.0), which permits unrestricted use, distribution, and reproduction in any medium, provided the original work is properly cited.

\section{INTRODUCTION}

Bone marrow examination is an extremely useful diagnostic tool for evaluation and diagnosis of not only hematological disorders but also numerous non-hematological diseases. Bone marrow examination is a relatively safe and invasive procedure, and leads to early diagnosis and specific management of the case ${ }^{1,2}$. There is no contraindication of bone marrow technique. It provides the opportunity of directly examining the tissue which forms blood cells ${ }^{3}$.

During first decade of twentieth century bone marrow was obtained from a patient as investigative procedure and as a diagnostic tool. Sternal aspiration was commenced in 1920. Arinkin introduced the use of needle aspiration of bone marrow in 1929. Since 1950s core needle biopsy has also been widely used as a diagnostic technique ${ }^{4}$.

Bone marrow aspiration (BMA) and bone marrow biopsy (BMB) are the two basic and important methods for bone marrow examination. BMA involves suction of liquid bone marrow and trephine biopsy provides solid core of bone. BMA provides cytological details of developing cells whereas $\mathrm{BMB}$ is a histopathological

Correspondence: Dr Sunila Tashfeen, Classified Haematologist, Combined Military Hospital Rawalpindi Pakistan

Received: 14 Oct 2019; revised received: 24 Apr 2020; accepted: 15 Jun 2020 study which helps in assessment of cellularity and infiltration ${ }^{5}$. Both techniques provide distinct information which is complimentary and supportive to each other in reaching a conclusive diagnosis ${ }^{6,7}$. Bone marrow involvement can be seen in both haematological and non-haematological disorders. Bone marrow disease can present with clinical symptom along with peripheral blood involvement as cytopenias, leucocytosis, leukoerythroblastic picture and many more. However peripheral blood picture cannot depict the exact stage and nature of disease ${ }^{8}$.

BMA is a simple and safe test that may either verify clinically expected diseases or may provide the previously unsuspected diagnosis ${ }^{9}$. Present study was designed to statistically analyse the data of patients who underwent bone marrow examination and to determine the prevalence and frequency of haematological and non haematological disorders diagnosed in this part of the country. It also evaluated the common indications of this technique, age distribution, male to female ratio, comparison of both techniques and ultimately the conclusions drawn.

\section{METHODOLOGY}

This prospective observational study was conducted in department of Pathology, Combined Military Hospital Quetta, from January 2018 to May 2019. A 
total of 101 patients, whom underwent bone marrow examination during study period through universal sampling method, were included. Patients were selected by non-probability consecutive sampling. Cases in which both BMA and BMB were done included in the study and comparative evaluation was carried out whereas cases in which only BMA was done were excluded from this study. Brief history, clinical examination and indication of procedure was also endorsed in a questionnaire designed for the study.

Whole procedure of bone marrow technique was explained to each patient. Informed consent was also obtained. Bone marrow examination was carried out using local anaesthetic technique under strict aseptic measures. BMA smears were stained by Leishman's stain, Giemsa stain and Perl's Prussian stain for iron. Positive control was also used to demonstrate iron. Cytochemical stains including Sudan Black B (SBB) and Leucocyte Alkaline Phosphatase (LAP) were also used wherever indicated. Each smear was assessed for cellularity, cytology and quantity of erythroid, myeloid, megakaryocytes and abnormal cells in bone marrow. Minimum of 500 nucleated cells (myelogram) were examined in bone marrow smear.

BMB were extracted from posterior iliac crest and fixed by using $10 \%$ neutral buffered formalin. Decalcification was done by $5-10 \%$ Nitric acid in 2-3 days. Later on biopsy was embedded in paraffin and 2-4 um thick sections were cut and stained using Haematoxylin and Eosin method. Furthermore, Reticulin stain was done to grade fibrosis.

Institutional ethical review board (IRB approval no. Ext-23-05/READ-IRB/007) approved this study. Statistical analysis was done using SPSS-22. Quantitative variables were presented by mean and $S D$ whereas qualitative variables were expressed as frequency and percentage.

\section{RESULTS}

A total of 101 patients underwent bone marrow examination. Table-I shows age and gender distribution of the patients. Mean age of the patients was $32.3 \pm$ 18.4 years and ranged from 4 months to 75 years and majority of the patients were in second decade of their life. Figure shows the clinical indications for bone marrow examination. Pyrexia of unknown origin (PUO) was the most common clinical indication with frequency of 21 (20.7\%) followed by pancytopenia 19 (18.8\%).

Table-II shows diagnosis drawn from bone marrow examination. Nutritional deficiency was the most common diagnosis with 18 cases followed by Acute leukaemia and Idiopathic thrombocytopenic purpura with 11 cases each. Four cases showed diluted marrow on BMA and unfit for opinion however on BMB diagnosed with lymphoproliferative disorder, hypoplastic marrow, megaloblasticanaemia and normocellular respectively. Fourteen bone marrow cases were normocellular on both BMA and BMB.

Table-I: Age and gender distribution of study subjects.

\begin{tabular}{l|c|c|c}
\hline Age (Years) & $\mathbf{n ~ ( \% )}$ & $\begin{array}{c}\text { Male, } \\
\mathbf{n}(\mathbf{\%})\end{array}$ & $\begin{array}{c}\text { Female, } \\
\mathbf{n}(\mathbf{\%})\end{array}$ \\
\hline $0-10$ & $10(9.9)$ & $6(5.9)$ & $4(3.9)$ \\
\hline $11-20$ & $14(13.8)$ & $7(6.9)$ & $7(6.9)$ \\
\hline $21-30$ & $33(32.6)$ & $25(24.7)$ & $8(7.9)$ \\
\hline $31-40$ & $18(17.8)$ & $15(14.8)$ & $3(2.9)$ \\
\hline $41-50$ & $8(7.9)$ & $6(5.9)$ & $2(1.9)$ \\
\hline $51-60$ & $6(5.9)$ & $4(3.9)$ & $2(1.9)$ \\
\hline $61-70$ & $10(9.9)$ & $3(2.9)$ & $7(6.9)$ \\
\hline
\end{tabular}

Table-II: Diagnosis of bone marrow examination.

\begin{tabular}{c|l|c}
\hline $\begin{array}{l}\text { S. } \\
\text { No }\end{array}$ & Diagnosis & n (\%) \\
\hline 1 & Nutritional Deficiency Anaemia & $18(17.8)$ \\
\hline 2 & Acute Leukemia & $11(10.8)$ \\
\hline 3 & Idiopathic Thrombocytopenic Purpura & $11(10.8)$ \\
\hline 4 & Myeloproliferative Neoplasm & $8(7.9)$ \\
\hline 5 & Hypersplenism & $7(6.9)$ \\
\hline 6 & Dysplastic Marrow & $5(4.9)$ \\
\hline 7 & Anaemia of Chronic Disorder & $4(3.9)$ \\
\hline 8 & Hypocellular Marrow & $4(3.9)$ \\
\hline 9 & Erythroid Hyperplasia & $3(2.9)$ \\
\hline 10 & Myeloid Hyperplasia & $3(2.9)$ \\
\hline 11 & Marrow Showing Reactive Changes & $2(1.9)$ \\
\hline 12 & Chronic Granulomatous Infection & $2(1.9)$ \\
\hline 13 & Myelodysplastic Syndrome & $2(1.9)$ \\
\hline 14 & Lymphoproliferative disorder & $2(1.9)$ \\
\hline 15 & Gaucher Disease & $1(0.9)$ \\
\hline 16 & Diluted Marrow & $4(3.9)$ \\
\hline 17 & Normal Study & $14(13.8)$ \\
\hline & Total & $101(100)$ \\
\hline
\end{tabular}

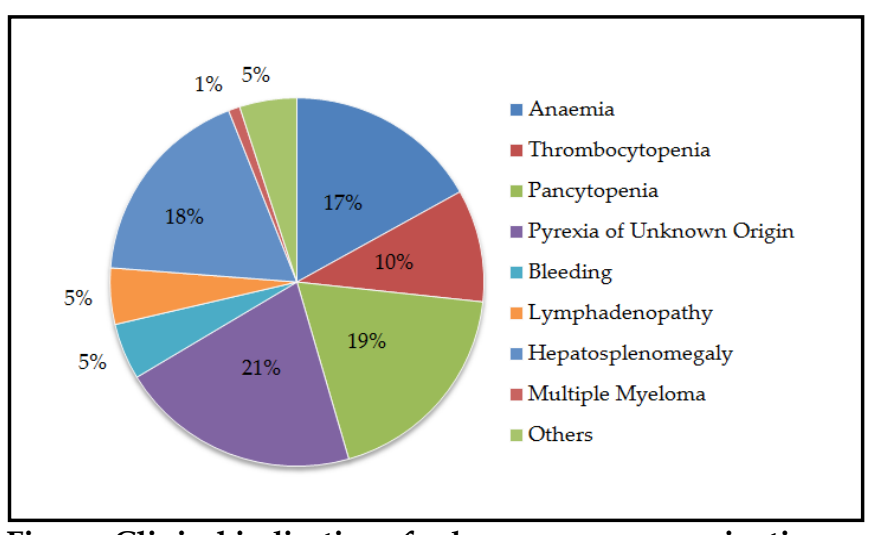

Figure: Clinical indications for bone marrow examination. 


\section{DISCUSSION}

Bone marrow examination is a significant investigation tool that can diagnose both haematological and non-haematological disorders in a short time. Bone marrow examination has many advantages as it provides diagnosis in significant number of cases $^{10}$. This diagnostic tool is very specific and a sensitive procedure and has a great clinical significance. It shortens patient's hospital stay as this diagnostic tool is rapid and less time consuming and definite treatment starts early ${ }^{11}$. Bone marrow aspiration and biopsy are essential techniques that not only complement each other but also enhance diagnostic accuracy in focal involvement of bone marrow.

Principle observation of our study was that nutritional anaemia was the most occurring haematological disorder identified in these patients i.e. 18 (17.8\%). Nutritional anaemia was identified most common disorder in other similar studies with a frequency ranging from $19 \%$ to $68 \%$. Our findings matched with study of Meenu, et al in which nutritional anaemia was $19 \%{ }^{10}$. Second most common disorder diagnosed was Immune thrombocytopenic purpura with a frequency of 11 $(10.8 \%)$.

Most common haematological malignancy in our study was Acute leukaemia $11(10.8 \%)$ and further distribution showed ALL being 7 (6.8\%) and AML 4 (3.9\%) which is contradictory to other similar studies such as Rahim et al and Srikanth et al in which AML had high frequency among haematological malignancies $^{11,12}$. Second most common haematological malignancy was Myeloproliferative Neoplasm constituting about $8(7.8 \%)$ and half of them were cases of Chronic Myeloid Leukemia in chronic phase ${ }^{13}$.

In our study most of the cases were diagnosed on bone marrow aspiration were consistent with trephine findings which is documented in other previous studies as by Ghodasara et al and Mahajan et al ${ }^{14,15}$. However chronic granulomatous inflammation was detected only on trephine biopsy in two of our cases ${ }^{16}$. Both of these cases presented with PUO and were diagnosed only on BMB. Similar results were exhibited in study by Daleep et al that all cases of granulomatous inflammation were diagnosed on bone marrow biopsy ${ }^{17}$. From this observations it is obvious that due to patchy involvement of bone marrow, BMB is necessary in diagnosis of granulomatous inflammation.

There were four diluted marrows which on trephine biopsy reported of having lymphoproliferative disorder, hypoplastic marrow, megaloblasticanaemia and normocellular marrow respectively. The main reason for diluted marrow was either due to packed marrow or fibrosis ${ }^{18}$. In case of dry tap or diluted marrow bone marrow biopsy should always accompany bone marrow aspiration before considering it as a result of faulty technique.

Most common clinical condition leading to bone marrow examination was PUO in twenty-one cases. These patients were diagnosed with Chronic granulomatous inflammation, ALL, Myelofibrosis, Gaucher's Disease, Anaemia of chronic disorders, Hypersplenism and with Reactive changes in marrow. Gupta et al study showed granulomas the most frequent finding $(76 \%)$ in $\mathrm{BMB}^{19}$. BMB increases etiological diagnosis in the presence of fibrosis and granulomas ${ }^{20}$.

There were few limitations of our study. Number of cases were less in sub groups so increase number of cases would have provided better correlation between BMA and BMB.

\section{ACKNOWLEDGEMENT}

All authors would like to extend thanks to participants of research and staff who were involved directly or indirectly.

\section{RECOMMENDATION}

In future study touch imprint should be included as an evaluating tool in bone marrow examination to further increase diagnostic accuracy and efficiency of procedure.

\section{Funding Source}

This research did not receive any specific grant from any funding agency in the public, commercial or not-for-profit sector.

\section{CONCLUSION}

This study has documented that bone marrow examination is a useful technique and although it is a confining procedure but should be performed when there is a distinct indication. Findings of bone marrow can modify the course of treatment. Thus procedure has a great diagnostic value. Both BMA and BMB are the complimentary techniques and supremacy of one method on other depends on the underlying disorder.

\section{CONFLICT OF INTEREST}

This study has no conflict of interest to be declared by any author.

\section{REFERENCES}

1. Bates I. Dacie and Lewis Practical Haematology. In: Mitchell Lewis, Barbara Bain, Imelda Bates, editors. Bone marrow biopsy. $12^{\text {th }}$ ed. Philadelphia: Churchill Livingstone 2016; 115-30. 
2. Bedu-Addo G, Ampem AY, Bates I. The role of bone marrow aspirate and trephine samples in haematological; diagnosis in patients referred to a teaching hospital in Ghana. Ghana Med J 2013; 47(2): 74-48.

3. Vijay M, Babita R, Jaspreet S, Surinder P, Pankaj K. Diagnostic utility of bone marrow aspiration, imprint and biopsy in evaluation of various haematological disorders. Int J Curr Res Med Sci 2018; 4(1): 28-36.

4. Barbara JB, David MC, Bridget SW. Bone marrow pathology. 4th Ed. Blackwell Publishing 2010: 5-8.

5. Verma S, Bansal R, Sharma S, Gupta A, Gupta M, Garg S, et al. Correlation between bone marrow aspiration and bone marrow biopsy with imprint smears in hematological disorders. National J Lab Med 2016; 5(3): 64-69.

6. Manoj KP, Santosh T, Atanu KB, Anita C, Jayanti N, Bodhistawa $B$, Parsad MD. Correlation of bone marrow aspiration and trephine biopsy in various haematological disorders: A study of 3 years. Ann Pathol Laboratory Med 2018; 5(3): 195-203.

7. Tooba F, Rajia L, Asima N. Comparison of diagnostic accuracy of bone marrow aspirate and trephine biopsy procedure. Ann Sep 2015; 21(3): 183-86.

8. Khan TA, Khan IA, Mahmood K. Diagnostic role of bone marrow aspiration and trephine biopsy in haematological practice. J Postgrad Med Inst 2014; 28(2): 217-21.

9. Atla BL, Anem V, Dasari A. Prospective study of bone marrow in haematological disorders. Int J Res Med Sci 2015; 3(8): 1917-21.

10. Meenu G, Monika G, Sunita S, Rajeev S. Comparison of bone marrow aspiration cytology with bone marrow trephine biopsy histopathology: An observational study. J Lab Physic 2017; 9(3): 182-89.

11. Vandana P, Pooja S, Mrinalini K, Meera S, Satendera S. Utility of simultaneous assessment of bone marrow aspirate and trephine biopsy sections in various haematological disorders. Iraqi J
Haematol 2018; 7(1): 26-32.

12. Shastry SM, Kolte SS. Spectrum of haematological disorders observed in one hundred and ten consecutive bone marrow aspirations and biopsies. Med J DY Patil Univ 2012; 5(2): 118-21.

13. Younus U, Saba K, Aijaz J, Bukhari MH, Naeem S. Significance of bone marrow histology in the diagnosis of acute myeloid leukaemia. Ann King Edward Med Unit 2011; 17(1): 5-8.

14. Ghodasara J, Gonsai RN. Comparative evaluation of simultaneous bone marrow aspiration and trephine biopsy-A tertiary care hospital based cross-sectional study. Int J Sci Res 2014; 10(1): 2058-61.

15. Mahajan V, Kaushal V, Thakur S, Kaushik R. A comparative study of bone marrow aspiration and bone marrow biopsy in haematological and non haematological disorders-An institutional experience. J Indian Acad Clin Med 2013; 14(2): 133-35.

16. Jeevan SK, Tara RP, Uppin S, Uppin M. Bone marrow granulomas. A retrospective study of 47 cases (a single centre experience). Am J Int Med 2014; 2(5): 90-94.

17. Daleep KK, Deepika M, Mangilal C. A relevance study of bone marrow aspiration and bone marrow biopsy in haematological and non haematological disorders. J Med Sci Clin Res 2017; 5(4): 20900-08.

18. Goyal S, Singh UR, Rusia U. Comparative evaluation of bone marrow aspirate with trephine biopsy in haematological disorders and determination of optimum trephine length in lymphoma infiltration. Mediterr J Hematol Infect Dis 2014; 6(1): e2014002.

19. Gupta R, Setia N, Aurora P, Singh S, Singh T. Hematological profile in pyrexia of unknown origin: role of bone marrow trephine biopsy vis-a-vis aspiration. Hematology 2008; 13(5): 307-12.

20. Chauhan S, Pradhan S, Mohanty R, Saini A. Bone marrow trephine biopsies: A single centre experience in Eastern India. Arch Med Health Sci 2017; 5(1): 34. 